\title{
Planète Cinéma
}

\section{Erhard Taverna}

Dr. med., Mitglied der Redaktion

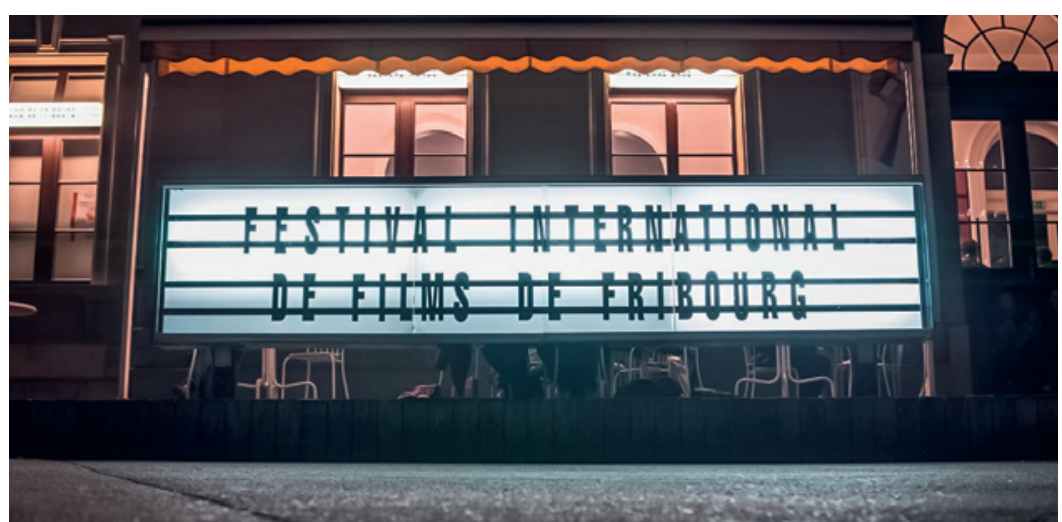

Mit dem Funiculaire in die Unterstadt. Der Saane entlang wandern, über die vielen Brücken gehen. Die Häuserfront über den steilen Sandsteinfelsen betrachten und dann die steilen, gepflasterten Gassen, an mächtigen Bürgerhäusern vorbei, das nächste Café aufsuchen. Ein märzlich wolkenloser Morgenhimmel, noch ist kaum jemand unterwegs. Es braucht diese Ruhe, bevor das Festival International de Films de Fribourg FIFF mit dem Mittagsfilm das Tagesprogramm eröffnet.

105 Filme aus 58 Ländern, in denen Frauen fast zur Hälfte die Regie führen. Die zweisprachige Stadt mit den vielen Studenten und der schönen Umgebung ist wunderbar geeignet, um das weltweite Filmschaffen in die Schweiz zu bringen. Alle Kontinente sind vertreten, dieses Jahr speziell die Karibik mit Haiti, Puerto Rico und der Dominikanischen Republik. Engagierte Filmschaffende erhalten eine Plattform für ihre Werke, die, oft unter schwierigen ökonomischen und politischen Bedingungen produziert, kaum in unsere Kinos gelangen. Armut und Gewalt, vor allem an Frauen, sind häufig ein Thema, aber auch Humor und Romantik kommen nicht zu kurz. Das Filmfestival wurde 1980 gegründet. Im Wettbewerb sind sowohl Dokumentar- als auch Spielfilme zugelassen. Zusätzliche Parallelsektionen zeigen ein Genrekino, dieses Jahr romantische Komödien, teilweise auch Klassiker, wie Breakfast at Tiffany's von Blake Edwards oder Bringing Up Baby von Howard Hawks. Mitternachtsvorführungen sorgten für anschliessende Alpträume.

Es gibt viele Filmfestivals, etwa Visions du Réel in Nyon oder Kurzfilmtage in Winterthur. Die Konzentration auf ein Tages- oder Wochenprogramm inklusive Rahmenveranstaltungen erlaubt eine vertiefte Sicht auf die kreativen Möglichkeiten bewegter Bilder. Über- raschende Entdeckungen sind möglich, das weite Panorama nimmt die Condition humaine in den Blick, die gewohnte Nabelschau im helvetischen Kuckucksheim weicht dem Bewusstsein, dass alle Menschen dieses Planeten die gleichen Probleme haben. Und noch etwas wird einem bewusst. Im täglichen Kino haben wir uns an eine leicht infantile Monokultur gewöhnt, die, neben der meist seichten Unterhaltung, vor allem Fluchtwelten und Ersatzhelden anbietet.

Die Zahl der Kinogänger ist rückläufig, für viele scheint auch das TV-Pantoffelkino eine Zumutung. Man möchte zu jeder Tageszeit, auf allen Geräten mit einem Internetzugang, aus einer riesigen Auswahl selbst auswählen können. Als Alternative zu Videotheken entstand ein DVD-Vertrieb per Post, der sich zu einem globalen Streamingdienst entwickelt hat. Allein in der Schweiz soll es über eine Million Netflix-Nutzer geben. Monatliche Abogebühren sorgen für einen Milliardenumsatz. Das Geschäftsmodell, mit dem die Kunden aus einem individualisierten Angebot auch Eigenproduktionen wählen können, ist einfach. Eine digitale Empfehlungsmaschine vermisst unablässig die Unterhaltungslandschaft durch die Auswertung der Nutzerdaten. Geschlecht, Hautfarbe, Nutzungszeiten, alles dient dazu, sich den Konsumenten anzupassen. Sie bekommen massgeschneidert, was ihren Erwartungen und Sehgewohnheiten entspricht. Eine Echokammer, in der ich nur höre, was ich schon kenne. Das Pendeln von A nach B wird zum Kinosaal. Was ich unterwegs auf meinem Tablett anschaue und anhöre, verkürzt mir, beliebig unterbrochen, die Bahnzeit. Kinofestivals, wie das in Fribourg, bieten ein Antidot, einen Kontrapunkt. Man muss sich über längere Zeit auf etwas einlassen. Sich auf unbekanntes Terrain vorwagen, entdeckungsfreudig Risiken und Nebenwirkungen in Kauf nehmen. Etwa bedrückende Erfahrungen oder Empörung aushalten, mit unbekannten Menschen mitleiden, in Gesellschaft lachen, Fachleute anhören, darüber diskutieren, Eindrücke vertiefen, ein Stück Welt nach Hause nehmen, das sonst für immer verborgen geblieben wäre. Im März 2020 ist es wieder so weit.

\section{Referenz}

Festival International de Films de Fribourg FIFF, März 2019.

Bildnachweis

(c) FIFF 